\title{
Recent Progress in Metal Oxide Based Materials as Anode Materials for Lithium- Ion Batteries
}

\author{
Lili Feng ${ }^{1,2, *}$, Changwei Su ${ }^{1,2}$, Zhewen Xuan ${ }^{1,2}$, Junming Guo ${ }^{1,2}$, Yingjie Zhang ${ }^{1,2}$ \\ ${ }^{1}$ Engineering Research Center of Biopolymer Functional Materials of Yunnan, Yunnan University of Nationalities \\ ${ }^{2}$ Key Laboratory of Ethnic Medicine Resource Chemistry, State Ethnic Affairs Commission \& Ministry of Education, School of Chemistry and \\ Biotechnology, Yunnan University of Nationalities, Kunming, China 650500 \\ * Corresponding author: lilylian2003@163.com
}

\begin{abstract}
Transition metal oxides are promising anode materials for Li-ion batteries due to their high theoretical capacity $\left(>600 \mathrm{mAhg}^{-1}\right)$, good rate capability, good safety, environmental friendliness and relatively low cost. In recent years, more and more investigators are motivating this advanced material rapidly towards their hybrid materials preparation to improve the cycling performance. Herein, we outlined the current research advances of transition metal oxides and their hybrid materials as anode materials for Li-ion batteries in the synthesis, lithium storage mechanism and electrochemical performance, with the aim of stimulating more research to achieve more useful application as soon as possible.
\end{abstract}

Keywords: Lithium-ion battery; Anode materials; Transition metal oxides; Electrochemical performance

Citation: L.L. Feng et al. Recent Progress in Metal Oxide Based Materials as Anode Materials for Lithium-Ion Batteries. Nano Biomed. Eng. 2013, 5(1), 57-64.

DOI: $10.5101 /$ nbe.v5i1.p57-64.

\section{Introduction}

In recent years, as the development of the economy, the requirement and consumption of energy is increasing. New green high-performance secondary power as a clean and efficient energy storage and conversion device, plays an important role in new energy exploitation and environmental protection, and has become one of the areas of worldwide competing for the development. Lithium-ion battery is widely used in mobile electronic devices, electric vehicles, alternate energy storage, smart electricity grid system and other fields [1], due to its high voltage, high energy, light weight, small size, low internal resistance, low self-discharge, long cycle life, no memory effect $[2,3]$. With the application range continuously extends, it requires significant improvements in many perspectives of lithium-ion battery, such as higher nergy density, larger power density, longer cycle life, safety and lower cost. The key to the success of development of novel and advanced rechargeable lithium-ion battery is the improvement of electrode materials.

Much effort had been devoted to improve the performance of LIBs up to now, among which a lot of research work focused on finding alternative anode materials. Currently, the commercial LIBs anode material was graphite, coke and non-graphitized carbon [4-6]. However, the theoretical capacity of graphite $\left(372 \mathrm{mAhg}^{-1}\right)$ could not be able to meet the needs of a new generation of high specific capacity LIBs. Now, the research focus of anode material for LIBs was mainly on the tin-based [79], silicon-based [10,11], antimony-based materials and the transition metal oxide materials [12-14]. Tin, silicon, and antimony-based anode materials were some of the most promising anode materials in view of the large theoretical capacity, rapid charge-discharge capacity, and easy to process, etc.. For examples, the theoretical specific capacity of tin-based materials was about twice larger than that of graphite's [15], and it was up to 4200 $\mathrm{mAhg}^{-1}$ of the silicon-based material. However, the following defects restricted the commercial application: 1. large volume change during charge and discharge process; 2. difficult to obtain good electrochemical performance when worked at high current density; 3 . high initial irreversible capacity loss. Therefore, new anode materials were desired. Intensive efforts had been devoted to explore new anode materials or design novel nanostructures. As early as 2000, Tarascon's research group reported that electrodes made of nanoparticles of transition-metal oxides ( $\mathrm{MO}$, where $\mathrm{M}$ is $\mathrm{Co}, \mathrm{Ni}, \mathrm{Cu}$ or Fe) demonstrated electrochemical capacities of $700 \mathrm{mAh}$ 
$\mathrm{g}^{-1}$ (this value was approximately twice of the theoretical capacity of the carbon material [12]), with $100 \%$ capacity retention for up to 100 cycles and high recharging rates for the first time. Up to now, the anode material research was mainly on various transition metal oxides and their composite materials, shuch as $\mathrm{Fe}_{3} \mathrm{O}_{4}, \mathrm{Co}_{3} \mathrm{O}_{4}, \mathrm{MnO}_{2}, \mathrm{SnO}_{2}$, $\mathrm{CuO}, \mathrm{MoO}_{2}, \mathrm{NiO}$, and $\mathrm{V}_{2} \mathrm{O}_{5}$. Chen group [15] reported $\alpha-\mathrm{Fe}_{2} \mathrm{O}_{3}$ nanotubes were synthesized by templating method and studied as LIBs anode materials. It was found that the as-prepared $\alpha-\mathrm{Fe}_{2} \mathrm{O}_{3}$ nanotubes, characterized by uniform size and shape with a high specific surface area, exhibited superior electrochemical activity, with a discharge capacity of $1415 \mathrm{mAhg}^{-1}$ at $100 \mathrm{mAg}^{-1}$ and $20{ }^{\circ} \mathrm{C}$. Xie group [16] prepared $\mathrm{SnO}_{2}$ hollow sphere and rod materials by the oxidation-crystallization method of amorphous colloids. The measured capacities of $\mathrm{SnO}_{2}$ hollow sphere and rod electrodes were 698 and 470 $\mathrm{mAhg}^{-1}$, respectively. And they were higher than that of a solid $\mathrm{SnO}_{2}$ nanoparticles electrode $\left(650 \mathrm{mAhg}^{-1}\right)$. Hu et al [17] prepared the 3D hollow dendritic shaped $\mathrm{CuO}$ materials, and the average coulombic efficiency was up to $97.0 \%$ in 50 week cycle when discharged at $0.5 \mathrm{C}$. Therefore, many attempts to obtain variety of transition metal oxides and their composite materials with excellent electrochemical performance had been carried out.

Herein, we outlined the current research advances of transition metal oxide materials as anode materials for LIBs in lithium storage mechanism, transition metal oxide nanomaterial preparation, hollow structure and core-shell structure construction of transition metal oxide materials, with an aim of stimulating more research to construct new metal oxide anode materials with high specific capacity, cycling performance, high coulombic efficiency, good rate capability and good safety, and achieve practical application as soon as possible.

\section{Lithium storage mechanism and the defect of transition metal oxide materials}

Up to now, there were three categories of LIBs anode materials, such as graphite, tin, silicon, antimony-based materials and the transition metal oxide materials. The lithium storage mechanisms of the three of the material types were different from each other. Graphite, a layered intercalation compound, was one of the most widely used lithium anodes. Lithium could be reversible inserted and extracted into the layered structure during the discharge/ charge process. The lithiated compounds had stable phases up to the $\mathrm{LiC}_{6}$ stoichiometry corresponding to a theoretical specific capacity of $372 \mathrm{mAhg}^{-1}$. Tin, silicon, antimony-based materials had specific capacity much higher than the conventional graphite.

The lithium storage mechanism of the tin, silicon, antimony-based materials were based on the alloying and dealloying of $\mathrm{Li}$ and $\mathrm{Sn}, \mathrm{Si}$, or $\mathrm{Sb}$ in the discharge/charge process. The detailed reaction was as follows:

$$
\mathrm{Si}(\mathrm{Sn})+\mathrm{Li}^{+}+\mathrm{xe}^{-} \rightleftarrows \operatorname{LixSi}(\mathrm{Sn}), \mathrm{X}_{\text {max }}=4.4
$$

Although, both the lithium storage mechanism of the two materials were the same, Si was much more appealing for the relatively high content on the earth, and larger theoretical specific capacity which up to 4198 $\mathrm{mAhg}^{-1}$ (about four times of the Sn electrode, 11 times of the graphite electrode). Unfortunately, there were 300\% volume expansion during the alloying process of $\mathrm{Li}$ and $\mathrm{Sn}$ or $\mathrm{Si}$, which suggested the destruction of the material integrity due to the enormous mechanical stress and pulverizes even if good reversibility during the charge/ discharge cycles.

Besides the intercalation compounds and metal alloys, another category of anodes were based on a conversion reaction, such as transition-metal oxides (MO, where $\mathrm{M}$ is $\mathrm{Co}, \mathrm{Ni}, \mathrm{Cu}$ or $\mathrm{Fe}$ and so on). The mechanism of Li reactivity differed from the classical Li insertion/ deinsertion or Li-alloying process, and involved the formation and decomposition of $\mathrm{Li}_{2} \mathrm{O}$, accompanying the reduction and oxidation of metal nanoparticles respectively. The detailed reaction was as follows:

$$
\mathrm{M}_{\mathrm{x}} \mathrm{O}_{\mathrm{y}}+2 \mathrm{yLi} \rightleftarrows \mathrm{yLi}_{2} \mathrm{O}+\mathrm{xM}
$$

The formation of $\mathrm{Li}_{2} \mathrm{O}$ and $\mathrm{M}$ was thermodynamically feasible. During the initial discharge process, $\mathrm{M}_{\mathrm{x}} \mathrm{O}_{\mathrm{y}}$ nanoparticles were fully reduced by $\mathrm{Li}$, which led to the formation of metallic $\mathrm{M}$ with nanosize and $\mathrm{Li}_{2} \mathrm{O}$ nanoparticles. The generating metallic $\mathrm{M}$ was of high activity and dispersed in a lithia $\left(\mathrm{Li}_{2} \mathrm{O}\right)$ matrix, with the $\left(\mathrm{Li}_{2} \mathrm{O}\right.$ nanoparticles) being surrounded by a solid electrolyte interface. The following charge process was inverse. The metallic $\mathrm{M}$ produced in the discharge process reacted with $\mathrm{Li}_{2} \mathrm{O}$, leading to the formation of nano transition metal oxides $\mathrm{M}_{\mathrm{x}} \mathrm{O}_{\mathrm{y}}$ and $\mathrm{Li}$. Indeed, $\mathrm{Li}_{2} \mathrm{O}$ had always been reported to be electrochemically inactive, especially when reacted with tin, silicon, antimony-based materials. However, in this case, the electrochemically driven size confinement of the metal particles was thus believed to enhance their electrochemical activity towards the formation/decomposition of $\mathrm{Li}_{2} \mathrm{O}$. So, the cycling performances of the transition metal oxides materials as anode materials depended extremely on their degree of division or aggregation.

The theoretical specific capacities of the transition metal oxides materials could be calculated by:

$$
\mathrm{C}=(\mathrm{F} * \mathrm{n}) /\left(\mathrm{Mw}^{*} 3.6\right)
$$

Where F was Faraday's constant $\left(96500 \mathrm{C} \mathrm{mol}^{-1}, 3.6\right.$ $\mathrm{C}=1 \mathrm{mAh}$ ), $\mathrm{n}$ was the Li molar number which could be inserted into or react with the active material for per mole of active material, and $\mathrm{Mw}$ was the molar mass of the active material $\left(\mathrm{g} \mathrm{mol}^{-1}\right)$. According to the formula, many theoretical specific capacities of transition metal oxides could be calculated. For example, the theoretical specific capacity of $\mathrm{NiO}$ was $718 \mathrm{mAhg}^{-1}, \mathrm{Fe}_{3} \mathrm{O}_{4}$ was $924 \mathrm{mAhg}^{-1}$, $\mathrm{Fe}_{2} \mathrm{O}_{3}$ was $1007 \mathrm{mAhg}^{-1}, \mathrm{MnO}_{2}$ was $1232 \mathrm{mAhg}^{-1}, \mathrm{CuO}$ was $670 \mathrm{mAhg}^{-1}, \mathrm{CoO}$ was $715 \mathrm{mAhg}^{-1}$. The transition metal oxides exhibited large rechargeable capacities 
which unrelated on the charge/discharge current and were much higher than that of the graphite $\left(372 \mathrm{mAhg}^{-1}\right)$. In addition, transition metal oxides materials had the advantages such as easy preparetion, low cost, high security, and similar redox potential to $\mathrm{Li}^{+} / \mathrm{Li}$. Therefore, transition metal oxides materials would act as promising candidates for electrode materials of LIBs.

Although transition metal oxides materials had large theoretical specific capacities, all these materials were generally plagued by large capacity loss during the initial cycle and poor cycling stability. There were two reasons for the large capacity loss during the initial cycle. (1) Transition metal oxides materials reacted with electrolyte resulting in the formation of a solid electrolyte interface (SEI) layer and possibly interfacial $\mathrm{Li}^{+}$storage. SEI film was known as a gel-like layer which contained ethylene oxide based oligomers, $\mathrm{LiF}, \mathrm{Li}_{2} \mathrm{CO}_{3}$, and lithium alkyl carbonate $\left(\mathrm{ROCO}_{2} \mathrm{Li}\right)$. The incompletely decomposition of SEI was the main reason for the large capacity loss during the initial cycle, which happened in all $3 \mathrm{~d}$ transition metal oxides. So the lithium storage capacities were usually higher than the theoretical capacity. (2) After the first discharge, the resulting transition metal $\mathrm{M}$ and $\mathrm{Li}_{2} \mathrm{O}$ could not be completely converted into $\mathrm{M}_{\mathrm{x}} \mathrm{O}_{\mathrm{y}}$ in the charge process.

There were three reasons for the poor cycling stability. (1) The electronic conductivity of transition metal oxides materials were usually low, and the electron or ion had difficults in the diffusion process, which resulting in irreversible electrode reaction and fast capacity decay. (2) After charge/discharge cycles, transition metal oxides suffered from enormous mechanical stress and pulverizes, leading to electrical contact loss between active particles and current collector. The transition metal oxides particles without electrical contact could no longer participate in the charge/discharge cycles, resulting in capacity fading. (3) The structural instability caused by gradual agglomeration of the metal grains, and the large volume change during phase transformation in the conversion reaction led to the capacity loss.

One effective way to mitigate these problems was to reduce the particle size of transition metal oxides to the nanometer scale. It was believed that the small particle size might short the diffusion length of the lithium ions, introduce ample contact area to the electrolyte as well as more active sites for lithium storage. Therefore, this article provided a simple overview on the nanostructured transition metal oxides materials and their hybrid materials as anode materials for LIBs.

\section{The preparation of transition metal oxide materials and their electrochemical performance}

The transition metal oxides as LIBs anode materials usually included $\mathrm{SnO}_{2}, \mathrm{CoO}, \mathrm{NiO}, \mathrm{CuO}, \mathrm{Cu}_{2} \mathrm{O}, \mathrm{Fe}_{2} \mathrm{O}_{3}$, $\mathrm{Fe}_{3} \mathrm{O}_{4}, \mathrm{MnO}_{2}$ and so on. Among these transition metal oxides, $\mathrm{SnO}_{2}$ was the most widely investigated because of their large capacity, environmental acceptability and low cost. The lithium storage mechanism was a little different as the traditional metal oxides for its two-step lithium storage. In the first process, $\mathrm{SnO}_{2}$ was reduced to metallic $\mathrm{Sn}$. The second process was the Sn alloying/de-alloying reaction with lithium. The overall electrochemical processes could lead to a total of $8.4 \mathrm{Li}$-ions insertion per formula unit of $\mathrm{SnO}_{2}$. This corresponded to a theoretical capacity of $1491 \mathrm{mAhg}^{-1}$. H.K. Liu et al [18] reported on the preparation of $\mathrm{SnO}_{2}$ nanowires by thermal evaporation process. The high purity $\mathrm{SnO}$ and $\mathrm{Sn}$ powders were mixed and mechanical milling for $40 \mathrm{~h}$ under an atmosphere of argon. Then, the ball-milled powder was placed in an alumina boat located inside a tube furnace, and silicon substrates without metal catalysts were placed downstream at a distance of about $15 \mathrm{~cm}$ from the powder to deposit $\mathrm{SnO}_{2}$ nanowires. The $\mathrm{SnO}_{2}$ nanowires showed initial capacity of $1134 \mathrm{mAhg}^{-1}$, and the capacity reduced to $250 \mathrm{mAhg}^{-1}$ at the 50th cycle. In this report, traditional $\mathrm{SnO}_{2}$ power was used as contrast. The initial capacity of the traditional $\mathrm{SnO}_{2}$ power was about $580 \mathrm{mAhg}^{-1}$, and the capacity reduced to $100 \mathrm{mAhg}^{-1}$ at the 50 th cycle.
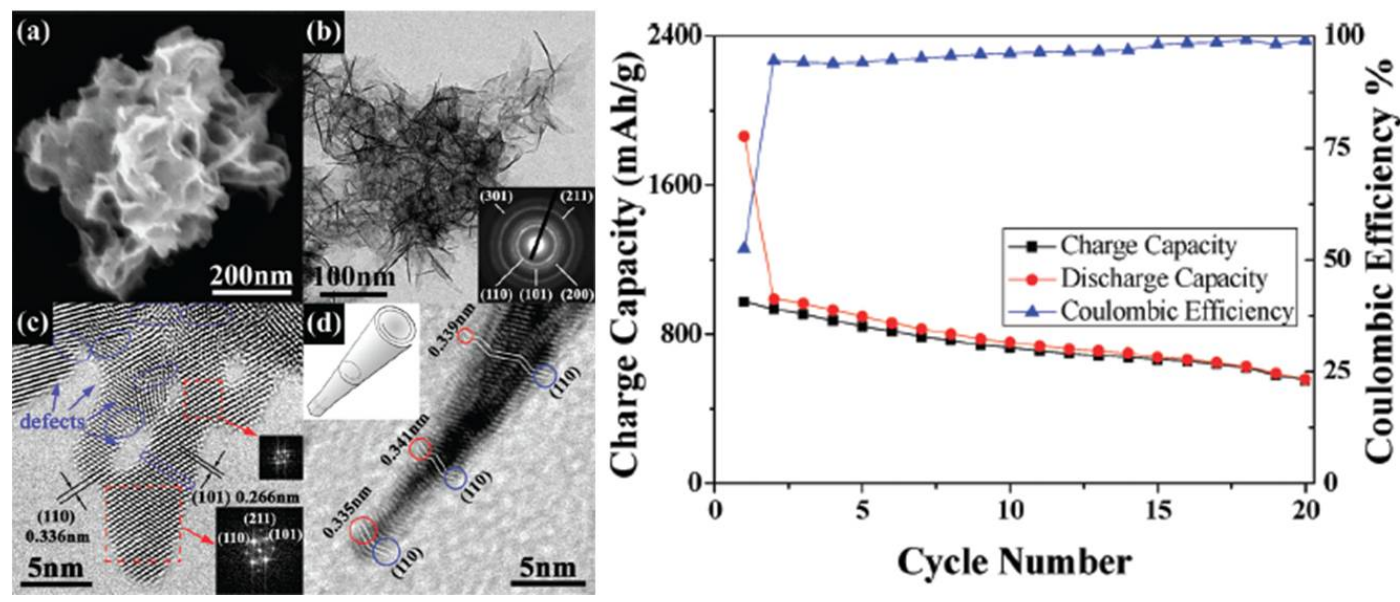

Figure 1 SEM image, TEM image, SAED pattern, and HRTEM images of the as-prepared $\mathrm{SnO}_{2}$ nanosheets (left). Charge and discharge capacities as well as Coulombic efficiency as a function of cycle number with $\mathrm{SnO}_{2}$ electrode in button cell (right). Reprinted with permission from C. Wang, Y. Zhou, M.Y. Ge, X.B. Xu, Z.L. Zhang, J.Z. Jiang, J. Am. Chem. Soc. 2010, 132, $46-47$ by ACS publication. 

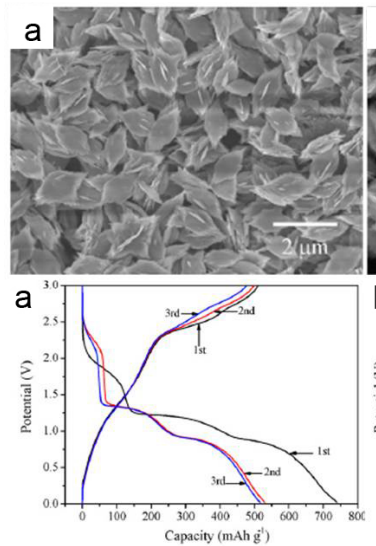
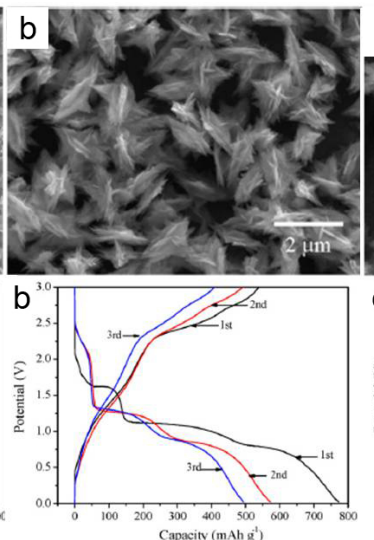
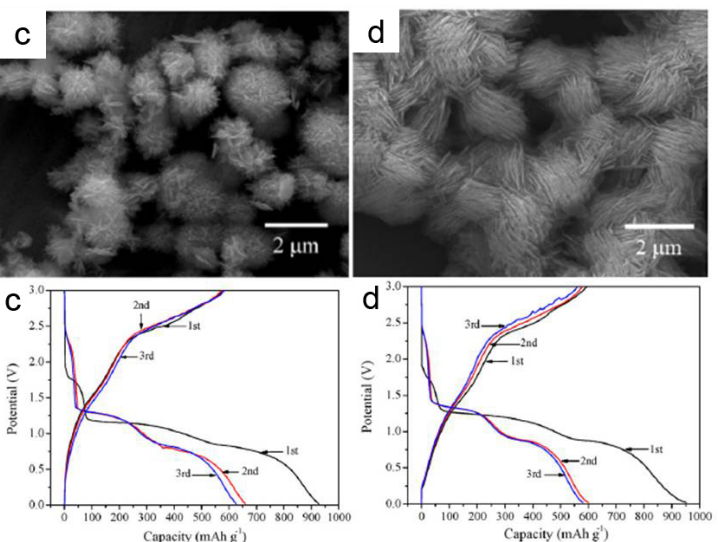

Figure 2 SEM images and the discharge-charge curves of $\mathrm{CuO}$ particles obtained under different $\mathrm{pH}$ conditions: (a) $\mathrm{pH} 9.5$; (b) $\mathrm{pH}$ 10; (c) $\mathrm{pH}$ 11 and (d) pH 11.5. Reprinted with permission from J.Y. Xiang, J.P. Tu, L. Zhang, Y. Zhou, X.L.Wang, S.J. Shi, J. Power Sources, 2010, 195, 313-319 by Elsevier publication.

The improvement of electrochemical behavior could be attributed to the $1 \mathrm{D}$ nanowire structure with a large surface area and high length/diameter ratio. The smaller diameter of the nanowires provided a short diffusion length for $\mathrm{Li}^{+}$insertion, which could enhance the charge transfer and electron conduction along the length direction. J.Z. Jiang et al [19] reported highly porous $\mathrm{SnO}_{2}$ nanometer-sized sheets synthesized from a hydrothermal reaction (the morphology and electrochemical cycle performance of the $\mathrm{SnO}_{2}$ nanosheets were shown in Figure 1). The morphology of the assembled nanosheets revealed a three-dimensional, flower-like appearance. The $\mathrm{SnO}_{2}$ nanosheets exhibited a high discharge capacity of 559 $\mathrm{mAhg}^{-1}$ after 20 cycles with the retention of $57 \%$.

$\mathrm{CuO}$ was another promising material as LIBs anode materials as for its advantages of high theoretic capacity, inexpensive, non-toxic, easily produced, and readily stored. J.Y. Xiang et al [20] had synthesized hierarchical $\mathrm{CuO}$ particles with various morphologies such as leaf, shuttle, flower, dandelion, and caddice clew by dehydration and re-crystallization of precursor $\mathrm{Cu}(\mathrm{OH})_{2}$ (shown in Figure 2). The initial capacity were 740 $\mathrm{mAhg}^{-1}, 773 \mathrm{mAhg}^{-1}, 841 \mathrm{mAhg}^{-1}, 927 \mathrm{mAhg}^{-1}, 952$ $\mathrm{mAhg}^{-1}$ respectively, and the initial coulombic efficiencies were $69.1 \%, 69.5 \%, 71.1 \%, 62.1 \%$ and $62.5 \%$. The low coulombic efficiency and large capacity loss during the initial cycle could be attribute to the incompletely decomposition of SEI film. In the subsequent charge/ discharge cycles, the charge capacity was $400 \mathrm{mAhg}^{-1}$. Compared to the theoretical capacity, the reversible capacity was not ideal. Tarascon research group [21,22] pointed out that $\mathrm{Li}^{+}$reacted with $\mathrm{CuO}$ in the discharge process, resulting elemental copper. But in the charge process, elemental copper could not be oxidized to the divalent state, and was usually oxidized to a monovalent state. Thus, the $\mathrm{CuO}$ samples had about $50 \%$ capacity loss.

B. V. R. Chowdari et al [23] prepared nanoflakes $\alpha-\mathrm{Fe}_{2} \mathrm{O}_{3}$ on $\mathrm{Cu}$ foil by using radio frequency magnetron sputtering method. The morphology of the as-prepared $\alpha-\mathrm{Fe}_{2} \mathrm{O}_{3}$ nanoflakes was shown in Figure 3. The samples exhibited a stable capacity of $(680 \pm 20) \mathrm{mAhg}^{-1}$ with no noticeable capacity fading up to 80 cycles when cycled in the voltage range $0.005-3.0 \mathrm{~V}$ at $65 \mathrm{mAg}^{-1}(0.1 \mathrm{C}$ rate). The capacity fading from the initial $1200 \mathrm{mAhg}-$ 1 to $680 \mathrm{mAhg}^{-1}$ regarded to its detailed lithium storage mechanism. After the $\alpha-\mathrm{Fe}_{2} \mathrm{O}_{3}$ converted to elemental $\mathrm{Fe}$ in the discharge process, the elemental Fe could not reversibly converted to $\mathrm{Fe}^{3+}$ in the following charge process, but converted to $\mathrm{FeO}$, and the reversible charge/ discharge process were between $\mathrm{FeO}$ and $\mathrm{Li}_{2} \mathrm{O}$ after the initial charge/discharge process. Y. Xie et al [24] had prepared $\alpha-\mathrm{Fe}_{2} \mathrm{O}_{3}$ nanorods by hydrothermal method and the following calcined process. The initial discharge capacity were at the range of 900-1200 $\mathrm{mAhg}^{-1}$, whereas with poor cycle performance.

\section{Hollow and core-shell structure construction of transition metal oxide materials and their electrochemical performance}

The above examples of the transition metal oxides materials with nanostructure all showed large initial specific capacities, but suffered from large capacity loss
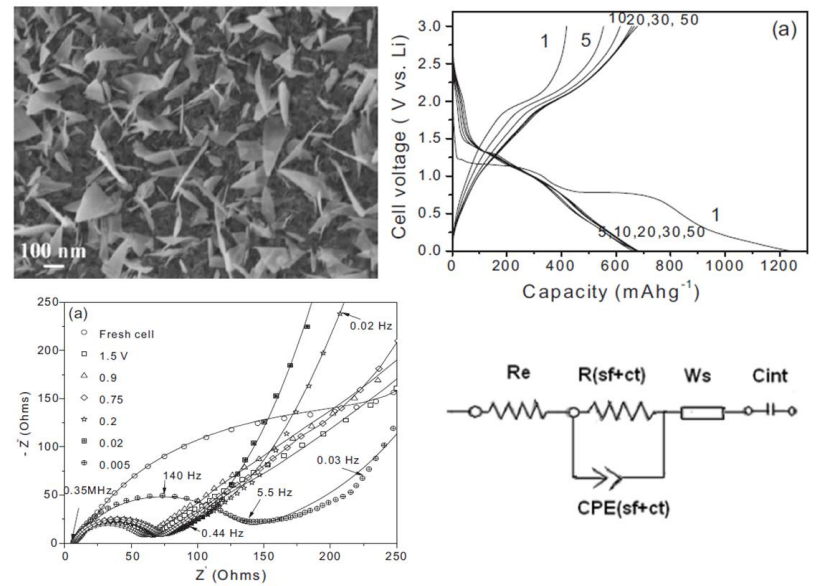

Figure 3 SEM image of $\alpha-\mathrm{Fe}_{2} \mathrm{O}_{3}$ nanoflakes grown on a $\mathrm{Cu}$ substrate; Galvanostatic charge-discharge curves in the voltage range 0.005-3.0 $\mathrm{V}$ (vs. Li) at a current of $65 \mathrm{mAg}^{-1}$. Nyquist plots ( $\mathrm{Z}^{\prime}$ vs. $\left.-\mathrm{Z}^{\prime \prime}\right)$ during the first cycle, at various voltages (Discharge cycle) and the fitted data. Reprinted with permission from M.V. Reddy, T. Yu, C.H. Sow, Z.X. Shen, C.T. Lim, G.V. Subba Rao, B.V.R. Chowdari, Adv. Funct. Mater. 2007, 17, 2792-2799 by WILEY publication. 
and poor cycling stability. Enormous mechanical stress and pulverizes occurred during the charge/discharge cycles were usually the reason. The agglomeration of the nano materials was another reason for the poor cycling stability. One effective way to mitigate these problems was to fabricate hollow structured or porous structure. The hollow interior provided extra free space for alleviating the structural strain and accommodating the large volume variation associated with repeated $\mathrm{Li}^{+}$ insertion/extraction processes, giving rise to improved cycling stability. Forthmore, the porous structure allowed for the easy diffusion of electrolyte into the inner region of the electrode. In this contribution, the hollow and porous structured metal oxides were discussed in this section.

$\mathrm{SnO}_{2}$ nano materials with hollow spherical morphology were widely researched. T. Hyeon et al [25] had prepared $\mathrm{SnO}_{2}$ hollow nanosphere by calcination of tin salt/ resorcinol-formaldehyde resin. The initial discharge capacity of the hollow $\mathrm{SnO}_{2}$ nano particles was about $1600 \mathrm{mAhg}^{-1}$, which was $600 \mathrm{mAhg}^{-1}$ higher than the solid $\mathrm{SnO}_{2}$ nano particles. Although the cycling stability was not very good, the hollow $\mathrm{SnO}_{2}$ nano particles still had $200 \mathrm{mAhg}^{-1}$ higher than the solid material. The detailed morphology and electrochemical performance were shown in Figure 4.

Pillow-shaped porous hollow $\mathrm{CuO}$ was prepared by a template-free method by L.H. Yue et al [26]. First, highly crystallized $\mathrm{CuC}_{2} \mathrm{O}_{4}$ precursor with micron-size in high dispersivity was prepared through a hydrothermal method. Then, porous hollow $\mathrm{CuO}$ was obtained by thermal treatment of the as-prepared precursor. From the second cycle, the discharge capacity persisted on about $400 \mathrm{mAhg}^{-1}$. It exhibited high average coulombic efficiency (98.3\%) and capacity retention $(83.3 \%$ of the discharge capacity of the second cycle after 50 cycles) at a current rate of $0.1 \mathrm{C}$, which could be seen in Figure 5.

Apart from spherical hollow nanoparticles, nano materials with specific shapes were also had been reported. For an example, X.W. Lou et al [27] reported a scalable synthesis of $\mathrm{Fe}_{2} \mathrm{O}_{3}$ microboxes with various shell structures based on simple annealing of preformed prussian blue (PB) microcubes. The strategy for synthesizing $\mathrm{Fe}_{2} \mathrm{O}_{3}$ microboxes was depicted in Figure 6. First, highly uniformed PB microcubes were synthesized. Then, PB microcubes were converted to $\mathrm{Fe}_{2} \mathrm{O}_{3}$ microboxes by subsequent thermal transformation process. There were three types of $\mathrm{Fe}_{2} \mathrm{O}_{3}$ microboxes, porous $\mathrm{Fe}_{2} \mathrm{O}_{3}$ microboxes, and hierarchical $\mathrm{Fe}_{2} \mathrm{O}_{3}$ microboxes. The $\mathrm{Fe}_{2} \mathrm{O}_{3}$ microboxes obtained with distinct morphologies and structures were displayed in Figure 6. The initial discharge capacities of the three samples were about 1200-1300 $\mathrm{mAhg}^{-1}$. Despite the initial capacity loss of ca. $20 \%$, which was considered quite low for transition metal oxide based anodes, all three samples displayed excellent cycling stability with almost no fading of capacity over the first 30 cycles. In particular, the hierarchical $\mathrm{Fe}_{2} \mathrm{O}_{3}$ microboxes exhibited the highest reversible capacity of $945 \mathrm{mAhg}^{-1}$ in the 30 th cycle. From the second cycle onward, the $\mathrm{Fe}_{2} \mathrm{O}_{3}$ microboxes exhibited a coulombic efficiency of $\sim 95 \%$.

All the above examples of hollow and porous structured transition metal oxides materials showed large initial specific capacities. Different to the solid nano materials, all the samples displayed excellent cycling stability. Apart from hollow and porous structure construction, shell coating were also an effective strategy to improve the cycling stability. Carbon coating was a widely used
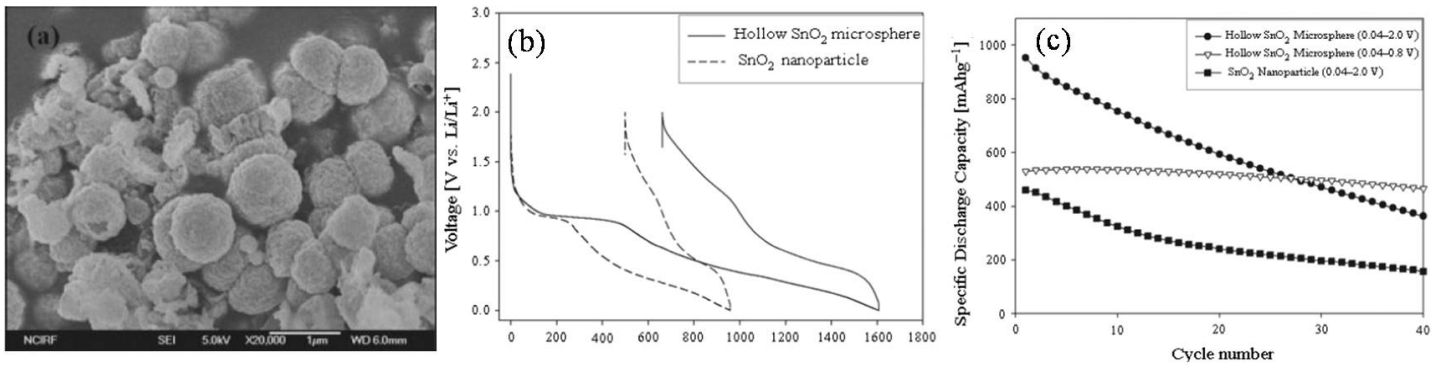

Figure $4 \mathrm{SEM}$ images, the galvanostatic charge-discharge curves in the voltage range 0.04-2.0 $\mathrm{V}$ of hollow $\mathrm{SnO}_{2}$ microspheres, and the cycling profile of hollow $\mathrm{SnO}_{2}$ microspheres and $\mathrm{SnO}_{2}$ nanoparticles. Reprinted with permission from S.J. Han, B. Jang, T. Kim, S.M. Oh, T. Hyeon, Adv. Funct. Mater. 2005, 15, 1845-1850 by WILEY publication.
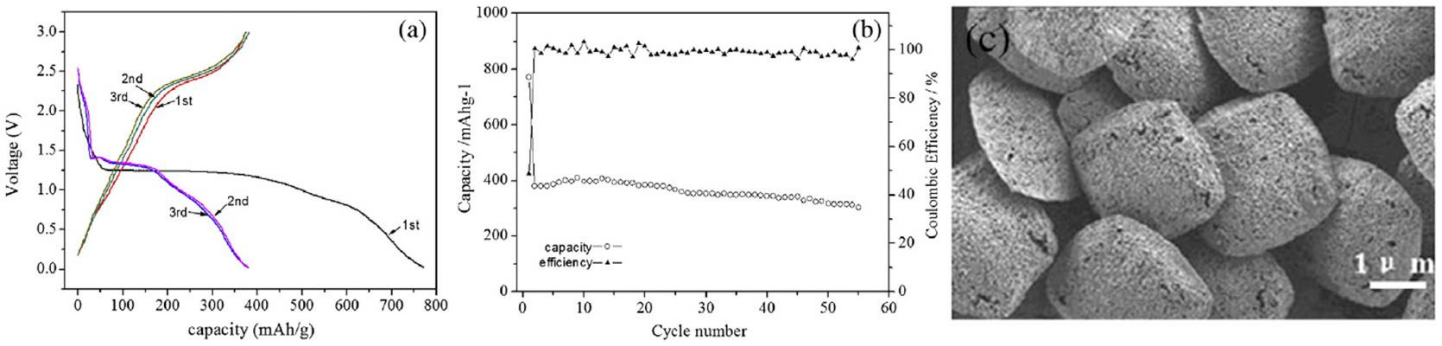

Figure 5 Charge-discharge curves, the cycling behavior and SEM images of the porous pillow-shaped CuO. Reprinted with permission from M. Wan, D.L. Jin, R. Feng, L.M. Si, M.X. Gao, L.H. Yue, Inorg. Chem. Comm. 2011, 14, $38-41$ by Elsevier publication. 
http://nanobe.org

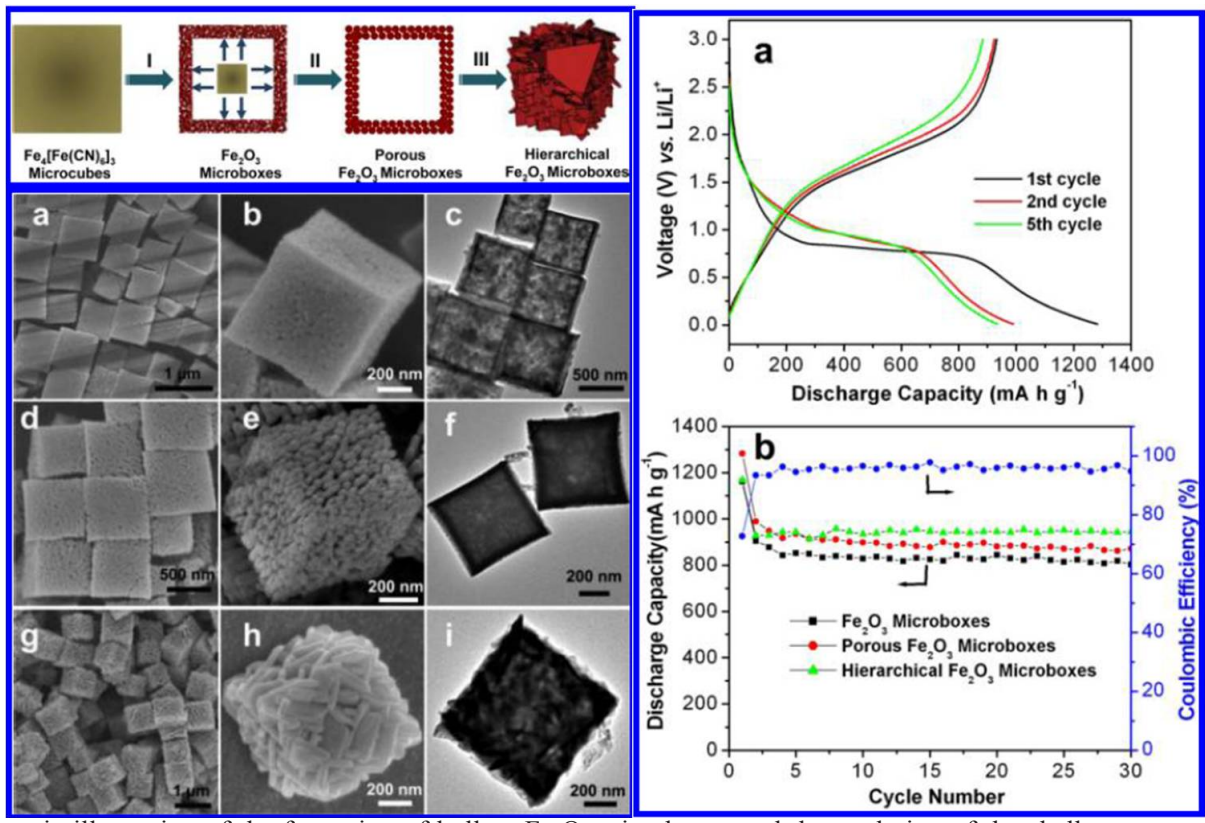

Figure 6 Schematic illustration of the formation of hollow $\mathrm{Fe}_{2} \mathrm{O}_{3}$ microboxes and the evolution of the shell structure with the increasing calcination temperature.(a, b, d, e, g, h) FESEM and (c, f, i) TEM images of hollow $\mathrm{Fe}_{2} \mathrm{O}_{3}$ microboxes obtained at (a, b, c) $350^{\circ} \mathrm{C},(\mathrm{d}, \mathrm{e}, \mathrm{f}) 550$ ${ }^{\circ} \mathrm{C}$, and $\left(\mathrm{g}\right.$, h, i) $650{ }^{\circ} \mathrm{C}$. Discharge-charge voltage profiles of porous $\mathrm{Fe}_{2} \mathrm{O}_{3}$ microboxes obtained at $550{ }^{\circ} \mathrm{C}$. (b) Cycling performance of $\mathrm{Fe}_{2} \mathrm{O}_{3}$ microboxes $\left(350{ }^{\circ} \mathrm{C}\right)$, porous $\mathrm{Fe}_{2} \mathrm{O}_{3}$ microboxes $\left(550^{\circ} \mathrm{C}\right)$, and hierarchical $\mathrm{Fe}_{2} \mathrm{O}_{3}$ microboxes $\left(650{ }^{\circ} \mathrm{C}\right)$ and Coulombic efficiency of porous $\mathrm{Fe}_{2} \mathrm{O}_{3}$ microboxes $\left(550^{\circ} \mathrm{C}\right.$ ) over the voltage range $0.01-3.0 \mathrm{~V} \mathrm{vs} \mathrm{Li} / \mathrm{Li}^{+}$at the same current density of $200 \mathrm{~mA} \mathrm{~g}^{-1}$. Reprinted with permission from L. Zhang, H.B. Wu, S. Madhavi, H.H. Hng, X.W. Lou, J. Am. Chem. Soc. 2012, 134, 17388-17391 by ACS publication.

strategy to improve the electrical conductivity of the electrode materials for LIBs. For example, Y.G. Guo and L.J. Wan et al [28] had synthesized monodispersed $\mathrm{Fe}_{3} \mathrm{O}_{4}$ spindles by a hydrothermal method. Then the as-prepared $\mathrm{Fe}_{3} \mathrm{O}_{4}$ spindles were mixed with glucose, and the mixture was transferred to a Teflon autoclave, and was heated at $190{ }^{\circ} \mathrm{C}$. The carbonprecursor coated hematite particles were harvested here. Then the sample was calcined in $\mathrm{N}_{2}$ atmosphere and the carbon coated $\mathrm{Fe}_{3} \mathrm{O}_{4}$ spindles could be obtained. The $\mathrm{Fe}_{3} \mathrm{O}_{4}-\mathrm{C}$ nanospindles showed high reversible capacity $\left(\sim 745 \mathrm{mAhg}^{-1}\right.$ at $\mathrm{C} / 5$ and $\sim 600 \mathrm{mAhg}^{-1}$ at $\mathrm{C} / 2$ ), high coulombic efficiency in the first cycle, as well as significantly enhanced cycling performance and high rate capability compared with bare hematite spindles and commercial magnetite particles. As shown in Figure 7, the first specific charge capacity of $\mathrm{Fe}_{3} \mathrm{O}_{4}-\mathrm{C}$ composite was as high as $749 \mathrm{mAhg}^{-1}$, approaching $\sim 93 \%$ of its theoretical specific capacity $\left(805 \mathrm{mAhg}^{-1}\right)$. The capacity of the composite remained unchanged through the subsequent four discharge/charge cycles. When cycles were tested at a relatively high current rate of $0.5 \mathrm{C}$ for the subsequent 80 cycles, the capacity of the bare $\alpha-\mathrm{Fe}_{2} \mathrm{O}_{3}$ and the commercial $\mathrm{Fe}_{3} \mathrm{O}_{4}$ faded to 250 and $300 \mathrm{mAhg}^{-1}$ immediately and then gradually decreased to 105 and $152 \mathrm{mAhg}^{-1}$, respectively. The capacity of $\mathrm{Fe}_{3} \mathrm{O}_{4}-\mathrm{C}$ composites also decreased to about $600 \mathrm{mAhg}^{-1}$, but the capacity remained $530 \mathrm{mAhg}^{-1}$ even after another 80 discharge/charge cycles, which is almost 5 times of
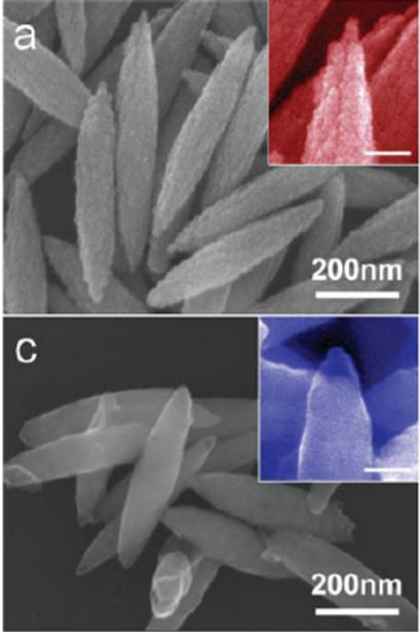
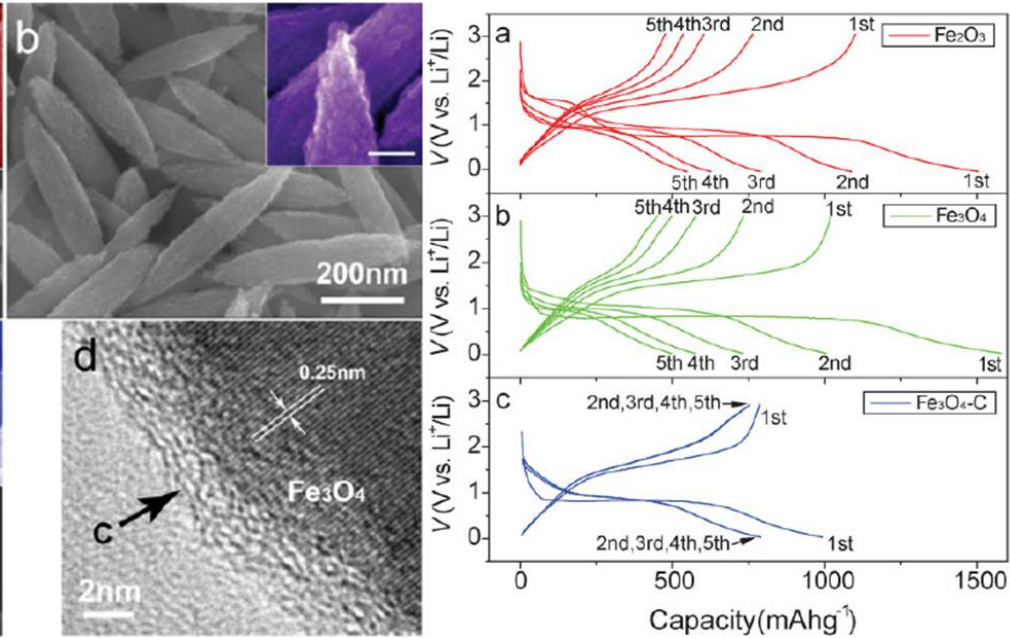

Figure 7 (a) SEM image of the as-synthesized hematite spindles. (b) SEM image of the carbon precursor coated hematite spindles. (c) SEM image of the carbon coated $\mathrm{Fe}_{3} \mathrm{O}_{4}$ spindles $\left(\mathrm{Fe}_{3} \mathrm{O}_{4}\right.$-C composites). (d) high-resolution TEM image of the $\mathrm{Fe}_{3} \mathrm{O}_{4}-\mathrm{C}$ composites. The insets are close views of corresponding samples, all unmarked scale bars are $50 \mathrm{~nm}$. And the discharge/charge profiles of (a) bare hematite spindles, (b) commercial magnetite particles, and (c) $\mathrm{Fe}_{3} \mathrm{O}_{4}-\mathrm{C}$ composites, at a current rate of C/5. Reprinted with permission from W.M. Zhang, X.L. Wu, J.S. Hu, Y.G. Guo, L.J. Wan, Adv. Funct. Mater. 2008, 18, 3941-3946 by WILEY publication. 
that of the bare $\alpha-\mathrm{Fe}_{2} \mathrm{O}_{3}$ spindles and 3.5 times of that of the commercial $\mathrm{Fe}_{3} \mathrm{O}_{4}$ particles. The improvements could be attributed to the uniform and continuous carbon coating layers, which have several functions, including: (1) maintaining the integrity of particles, (2) increasing the electronic conductivity of electrodes leading to the formation of uniform and thin solid electrolyte interphase (SEI) films on the surface, and (3) stabilizing the asformed SEI films. The results gave clear evidences of the utility of carbon coatings to improve the electrochemical performance of nanostructured transition metal oxides as superior anode materials for LIBs.

Apart from the the $\mathrm{Fe}_{3} \mathrm{O}_{4}-\mathrm{C}$ composite, $\mathrm{SnO}_{2} @$ carbon, CuO@carbon,oxides@ carbon composites were all prepared. The capacity of $\mathrm{CuO} @$ carbon composite was about $500 \mathrm{mAhg}^{-1}$ after 50 cycles. The capacity of $\mathrm{SnO}_{2} @$ carbon composite was about $500 \mathrm{mAhg}^{-1}$ after 100 cycles. They all indicated enhanced cycling performance. Y.D. Li et al [29] addressed a general and facile onepot hydrothermal method was developed to prepare oxide@C core-shell nanostructures with carbonaceous polysaccharide shells and oxides (including hydroxides or complex oxides) cores. The electrochemical characterization on calcined $\mathrm{SnO}_{2} @ \mathrm{C}$ nanostructures showed good cycling performance.

Graphene, as a new component of carbon materials, had also been used as coating shell in the LIBs anode materials. Y. Cui and H.J. Dai et al [30] developed twostep solution-phase reactions to form hybrid materials of $\mathrm{Mn}_{3} \mathrm{O}_{4}$ nanoparticles on reduced graphene oxide (RGO) sheets for lithium ion battery applications. The $\mathrm{Mn}_{3} \mathrm{O}_{4}$ nanoparticles formed on RGO showed a high specific capacity up to $\sim 900 \mathrm{mAhg}^{-1}$, near their theoretical capacity, with good rate capability and cycling stability, owing to the intimate interactions between the graphene substrates and the $\mathrm{Mn}_{3} \mathrm{O}_{4}$ nanoparticles grown atop. For the free $\mathrm{Mn}_{3} \mathrm{O}_{4}$ nanoparticles, the capacity was about 200 $\mathrm{mAhg}^{-1}$. The graphene hybridized composite showed 700 $\mathrm{mAhg}^{-1}$ higher in capability. So the $\mathrm{Mn}_{3} \mathrm{O}_{4} / \mathrm{RGO}$ hybrid could be a promising candidate material for a highcapacity, low-cost, and environmentally friendly anode for lithium ion batteries. Y.G. Guo et al [31] had developed $\mathrm{SnO}_{2} / \mathrm{RGO}$ hybrid, which had specific charge capacity of the composite was $786 \mathrm{mAhg}^{-1}$ in the first cycle and 558 $\mathrm{mAhg}^{-1}$ after 50 cycles. The cycling performance had been drastically improved. For the free $\mathrm{SnO}_{2}$ powder, the initial specific capacity was $838 \mathrm{mAhg}^{-1}$. After 50 cycles, the capacity decreased dramatically to $137 \mathrm{mAhg}^{-1}$, showing only $18 \%$ retention of its initial capacity. X.L. Feng et al [32] presented a two-dimensional (2D) coreshell nanostructure constructed by confining the welldefined graphene based metal oxides nanosheets (G@ MO) within carbon layers. The sample had both the advantages of graphene and could tackle the deformation of MO nanoparticles while keeping the overall electrode highly conductive and active in lithium storage. The G@ $\mathrm{SnO}_{2} @ \mathrm{C}$ sample had the capacity of $800 \mathrm{mAhg}^{-1}$ at the rate of $200 \mathrm{mAg}^{-1}$ after 100 cycles. The as-prepared G@
$\mathrm{Fe}_{3} \mathrm{O}_{4} @ \mathrm{C}$ sample had the capacity of $920 \mathrm{mAhg}^{-1}$ at the rate of $200 \mathrm{mAg}^{-1}$ after 100 cycles.

In summary, there are more and more researches on the transition metal oxides as LIBs anode materials. They usually focus on preparing transition metal oxides into nanometer scale with variaties of morphologies and the hollow and core-shell structures to improve their electrochemical performance. Although many studies have done on transition metal oxides as LIBs anode materials, this region even needs more powerful research. For examples, the issues now are how to transform these scientific results to practical application, and how to transform the laboratory synthesis to large scale industrial production.

\section{Conclusions}

Transition metal oxides are promising anode materials for Li-ion batteries due to their high theoretical capacity $\left(>600 \mathrm{mAhg}^{-1}\right.$ ), good rate capability, good safety, environmental friendliness and relatively low cost. But the disadvantage of this kind of materials is the poor cycling performance. To make materials into nanometer scale and hollow, core-shell structure could improve the cycling performance. Now most efforts have made on their hybrid materials preparation. But this region even needs more powerful research. For examples, the issues now are how to transform these scientific results to practical application, and how to transform the laboratory synthesis to large scale industrial production. We have long way to go in this research area to achieve the valuable application as soon as possible.

\section{Acknowledgments}

This work was financially supported by the National Natural Science Foundation of China (51062018, 51262031), the Natural Science Foundation of Yunnan (2010FXW004), Program for Innovative Research Team (in Science and Technology) in University of Yunnan Province (2010UY08, 2011UY09), and Yunnan Provincial Innovation Team (2011HC008), the youth fund research project of Yunnan University of Nationalities (2012QN01), and the general program of the application and basic research foundation of Yunnan province.

\section{References}

1 Tarascon J. M., Armand M., Issues and challenges facing rechargeable lithium batteries. Nature 2001, 414 (6861), 359-367.

2 Wu Y., Wan, C., Jiang c., Lithium-ion secondary battery. Chemical Industry Press 2002.

3 Wu Y., Dai X., Ma J., Cheng Y. Lithium-ion batteryApplications and Practice. Chemical Industry Press 2004.

4 Reeves S. D., Morris R. S. Improved MCMB anodes by surface modification with self-assembling nonionic surfactants. Electrochem. Solid St. Chem. 2004, 7 (8), B29-B30.

5 Mochida I., Ku C. H., Korai Y. Anodic performance and insertion mechanism of hard carbon prepared from synthetic isotropic pitches. Carbon 2001, 39 (3), 399-410.

6 EunJoo Y., Kim J., Hosono E., Hao-shen Z., Kudo T., Honma I. Large reversible Li storage of graphene nanosheet families for use in rechargeable lithium ion batteries. Nano Lett. 2008, 8 (8), 2277.

7 Wang F., Zhao, M.; Song, X., Nano-sized SnSbCux alloy anodes prepared by co-precipitation for Li-ion batteries. J. Power Sources 2008, 175 (1), 558-563.

8 Yu Y., Chen, C.H., Shi, Y. A tin-based amorphous oxide composite with a porous, spherical, multideck-cage morphology 
as a highly reversible anode material for lithium-ion batteries. Adv. Mater. 2007, 19 (7), 993-998

9 Min Gyu, K.; Jaephil, C., Nanocomposite of amorphous Ge and $\mathrm{Sn}$ nanoparticles as an anode material for Li secondary battery. J. Electrochem. Soc. 2009, 156 (4), A277-82.

10 Hu Y.S., Demir-Cakan R., Titirici M.-M., Mueller J. O., Schloegl R., Antonietti M., Maier J. Superior storage performance of a $\mathrm{Si} @ \mathrm{SiOx} / \mathrm{C}$ nanocomposite as anode material for lithium-ion batteries. Angew. Chem. Int. Ed. 2008, 47 (9), 1645-1649.

11 Cui L.F., Ruffo R., Chan C.K., Peng H., Cui Y. Crystallineamorphous core-shell silicon nanowires for high capacity and high current battery electrodes. Nano Lett. 2009, 9 (1), 491-495.

12 Poizot P., Laruelle S., Grugeon S., Dupont L., Tarascon J.M. Nano-sized transition-metaloxides as negative-electrode materials for lithium-ion batteries. Nature 2000, 407 (6803), 496-499.

13 Wang P.C., Ding H.P., Bark T., Chen C.H. Nanosized alpha$\mathrm{Fe}_{2} \mathrm{O}_{3}$ and $\mathrm{Li}-\mathrm{Fe}$ composite oxide electrodes for lithium-ion batteries. Electrochim. Acta 2007, 52 (24), 6650-6655.

14 Zhang D.W., Yi T.H., Chen C.H. Cu nanoparticles derived from $\mathrm{CuO}$ electrodes in lithium cells. Nanotechnology 2005,16 (10),2338-2341

15 Chen J., Xu L.N., Li W.Y., Gou X.L. alpha-Fe ${ }_{2} \mathrm{O}_{3}$ nanotubes in gas sensor and lithium-ion battery applications. Adv. Mater. 2005, 17 (5), 582-587.

16 Zhao Q., Xie Y., Dong T., Zhang Z. Oxidation-crystallization process of colloids: An effective approach for the morphology controllable synthesis of $\mathrm{SnO}_{2}$ hollow spheres and rod bundles. J. Phys. Chem. C 2007, 111 (31), 11598-11603.

17 Yingying H., Xintang H., Kai W., Jinping L., Jian J., Ruimin D., Xiaoxu J., Xin L. Kirkendall-effect-based growth of dendriteshaped $\mathrm{CuO}$ hollow micro/nanostructures for lithium-ion battery anodes. J. Solid St. Chem. 183 (3), 662-7.

18 Park M.S., Wang G.X., Kang Y.M., Wexler D., Dou S.X., Liu H.K., Preparation and electrochemical properties of $\mathrm{SnO}_{2}$ nanowires for application in lithium-ion batteries. Angew. Chem. Int. Ed. 2007, 46 (5), 750-753.

19 Wang C., Zhou Y., Ge M., Xu X., Zhang Z., Jiang J.Z. Large-scale synthesis of $\mathrm{SnO}_{2}$ nanosheets with high Lithium storage capacity. J. Am. Chem. Soc. 132 (1), 46-49.

20 Xiang J.Y., Tu J.P., Zhang L., Zhou Y., Wang X.L., Shi S.J. Self-assembled synthesis of hierarchical nanostructured $\mathrm{CuO}$ with various morphologies and their application as anodes for lithium ion batteries. J. Power Sources 195 (1), 313-319.

21 Grugeon S., Laruelle S., Herrera-Urbina R., Dupont L., Poizot P., Tarascon J.M. Particle size effects on the electrochemical performance of copper oxides toward lithium. J. Electrochem. Soc. 2001, 148 (4), A285-A292.
22 Debart A., Dupont L., Poizot P., Leriche J.B., Tarascon J.M. A transmission electron microscopy study of the reactivity mechanism of tailor-made $\mathrm{CuO}$ particles toward lithium. J. Electrochem. Soc. 2001, 148 (11), A1266-A1274.

23 Reddy M.V., Yu T., Sow C.H., Shen Z.X., Lim C.T., Rao G.V.S., Chowdari B.V.R. alpha- $\mathrm{Fe}_{2} \mathrm{O}_{3}$ nanoflakes as an anode material for Li-ion batteries. Adv. Funct. Mater. 2007, 17 (15), 2792-2799.

24 Wu C., Yin P., Zhu X., OuYang C., Xie Y. Synthesis of hematite (alpha- $\mathrm{Fe}_{2} \mathrm{O}_{3}$ ) nanorods: Diameter-size and shape effects on their applications in magnetism, lithium ion battery, and gas sensors. J. Phys. Chem. B 2006, 110 (36), 17806-17812.

25 Sangjin H., Byungchul J., Taeahn K., Oh S. M.,Taeghwan H. Simple synthesis of hollow tin dioxide microspheres and their application to lithium-ion battery anodes. Adv. Funct. Mater. 2005, 15 (11), 1845-50.

26 Mei W., Dalai J., Ran F., Limin S., Mingxia G., Linhai Y. Pillow-shaped porous $\mathrm{CuO}$ as anode material for lithium-ion batteries. Inorg. Chem. Commun. 14 (1), 38-41.

27 Zhang L., Wu H.B., Madhavi S., Hng H.H., Lou X.W. Formation of $\mathrm{Fe}_{2} \mathrm{O}_{3}$ microboxes with hierarchical shell structures from metal-Organic frameworks and their Lithium storage property. J. Am. Chem. Soc. 134 (42), 17388-17391.

28 Zhang W.M., Wu X.L., Hu J.S., Guo Y.G., Wan L.J. Carbon Coated $\mathrm{Fe}_{3} \mathrm{O}_{4}$ nanospindles as a superior anode material for Lithium-Ion batteries. Adv. Funct. Mater. 2008, 18 (24), 3941-3946.

29 Sun X., Liu J., Li Y. Oxides@C core-shell nanostructures: One-pot synthesis, rational conversion, and Li storage property. Chem. Mater. 2006, 18 (15), 3486-3494.

30 Wang H., Cui L.F., Yang Y., Casalongue H.S., Robinson J. T., Liang Y., Cui Y., Dai H. $\mathrm{Mn}_{3} \mathrm{O}_{4}$-graphene hybrid as a high-capacity anode naterial for Lithium-ion batteries. J. Am. Chem. Soc. 132 (40), 13978-13980

31 Zhang L.S., Jiang L.Y., Yan H.J., Wang W.D., Wang W., Song W.G., Guo Y.G., Wan L.J. Mono dispersed $\mathrm{SnO}_{2}$ nanoparticles on both sides of single layer graphene sheets as anode materials in Li-ion batteries. J. Mater. Chem. 20 (26), 5462-5467.

32 Su Y., Li S., Wu D., Zhang F., Liang H., Gao P., Cheng C., Feng X. Two-dimensional carbon-coated graphene/metal oxide hybrids for enhanced Lithium storage. Acs Nano 6 (9), 8349-8356.

Copyright:(c) 2013 L.L. Feng et al. This is an open-access article distributed under the terms of the Creative Commons Attribution License, which permits unrestricted use, distribution, and reproduction in any medium, provided the original author and source are credited. 